\title{
Nutritional and Medicinal value of Moringa oleifera
}

\author{
Amanjot Kaur \\ Department of Botany, D.A.V. College, Amritsar-143006 \\ *Corresponding Author: amanjotdav@gmail.com
}

Available online at: www.isroset.org

Received: 04/May/2018, Revised: 14/May/2018, Accepted: 13/Jun/2018, Online: 30/Jun/ 2018

\begin{abstract}
Moringa oleifera Lam is a highly valued plant which is found in many countries of the tropics and subtropics. All the parts of this tree are useful either for nutritional or Medicinal purposes. Various parts of this plant such as the leaves, roots, seed, bark, fruit, flowers and immature pods act as cardiac and circulatory stimulants, possess antitumor, anti inflammatory, antihypertensive, cholesterol lowering and antifungal activities and are being employed for the treatment of different ailments in the indigenous system of medicine, particularly in South Asia. For cooking, usually leaves, flowers and Pods are used. They possess miraculous health benefits. Bark and roots are used in traditional medicines. This tree has small leaves, white flowers and seed pods which are long, slender and triangular resembling drumsticks so this tree is also known as Drumsticks in English. Different parts of Moringa oleifera contain important minerals and are a good source of proteins, vitamins, betacarotene, amino acids and various phenolics. Moringa oleifera provides a rich and rare combination of zeatin, quercetin, betasitosterol, caffeoylquinic acid and kaempferol.
\end{abstract}

Keywords-Moringa oleifera, Cardiac, Drumsticks, Phenolics, Stimulants.

\section{Introduction}

Moringa oleifera is a plant which has been known for its health benefits for thousands of years. It is very rich in healthy antioxidants and bioactive plant compounds. Moringa oleifera Lam. tree is grown in many tropical and subtropical regions. As it grows in many tropic and subtropic regions worldwide so it is known by various names like horseradish tree, drumstick tree, ben oil tree, miracle tree, and "Mother's Best Friend" and that too due to different reasons. It is known as horseradish tree because of its ground root taste. This tree has small leaves, white flowers and seed pods which are long, slender and triangular resembling drumsticks so this tree is also known as Drumsticks in English. In Hindi it is known as Sahjan or Munga. In Tamil it is known as Murungai and in Malayalam it is known as Murunga. Also it is named as ben oil tree because of its seed-derived oils. Its leaves, pods and flowers are full of nutrients which are useful for both human and animals [1]. It is one of the 14 species of family Moringaceae. It is known as a food plant in Thai cuisine. Its leaves, seeds, bark, roots, sap, and flowers are widely used in traditional medicine. Also its leaves and immature seed pods are used as food products in human nutrition. Almost all its parts are used for its nutritional value, medicinal properties and for taste and flavor as a vegetable and seed. Its leaves can be eaten either fresh or cooked. These can be stored as a dried powder for many months without any major loss of its nutritional value. Its pods and leaves are usually eaten in parts of India and Africa [2]. Its leaves are an excellent source of many vitamins and minerals.

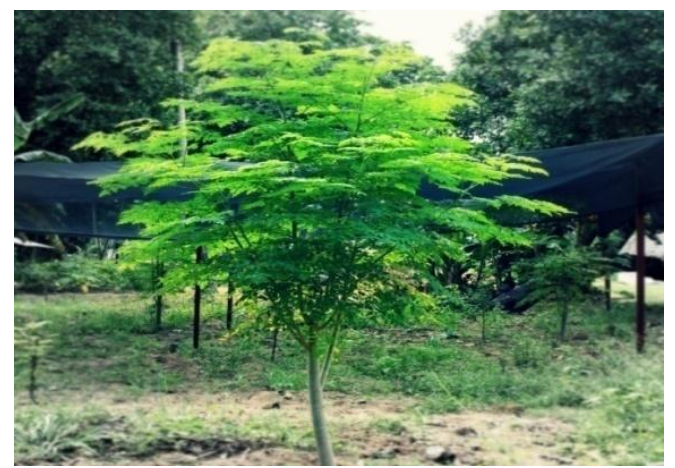

Fig 1 Moringa oleifera tree

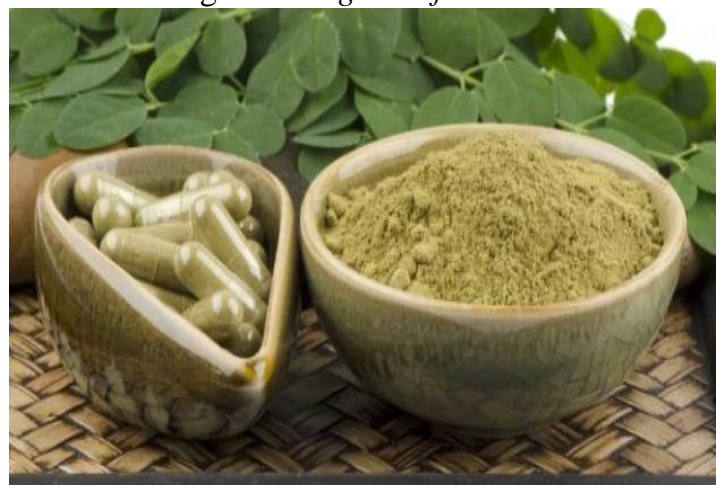

Fig 2 Moringa oleifera leaves, powder and capsules 


\section{Taxonomy and Botanical description of Moringa oleifera}

Classification

Domain: Eukaryota

Kingdom: Plantae

Phylum: Spermatophyta

Subphylum: Angiospermae

Class: Dicotyledonae

Order: Capparidales

Family: Moringaceae

Genus: Moringa

Species: oleifera

\section{Distribution}

Moringa oleifera is found all over the world in the tropic and sub tropic regions. Moringa oleifera is thought to be originated in northern India. It is an Indian native species. In its native range, Moringa oleifera is found in the tropical moist deciduous forests of northern India, southern tropical dry deciduous forests. Because of its value as food and medicine, it may have been introduced from India to Arabia, East Africa and South-East Asia by the early Indian Ocean traders for more than thousands years ago. It is probably now more widely present in other countries with a tropical climate. It is known to be very widespread in West Africa and Central America. Among Indian states, Andhra Pradesh leads in both area and production followed by Karnataka and Tamil Nadu. Moringa oleifera is grown in home gardens in West Bengal and Odisha and as living fences in southern India and Thailand. In Philippines and Indonesia, it is grown for its leaves which are used as food. Moringa oleifera is also actively cultivated by the World Vegetable Centre in Taiwan, a centre for vegetable research. In Haiti, it is grown as windbreaks and to help reduce soil erosion.

\section{Botanical characters}

Moringa oleifera is a fast-growing, deciduous tree. Moringa oleifera is a tree ranging in height from 5-12 $\mathrm{m}$ with an open umbrella-shaped crown having straight trunk $(10-30 \mathrm{~cm}$ thick) and a corky, whitish bark. Young shoots have purplish or greenish-white, hairy bark. The tree has a tuberous tap root which explains its tolerance to drought conditions. Generally considered a tree of hot semi-arid regions, Moringa oleifera is adaptable to a wide range of environmental conditions from hot and dry to hot, humid, wet conditions. Moringa oleifera grows more rapidly, reaching higher heights, when found in well-drained soils with ample water. It tolerates sandy soils, heavier clay soils and water limited conditions. The tree can grow in slightly alkaline soils up to $\mathrm{pH} 9$ as well as acidic soils as low as $\mathrm{pH}$ 4.5. It is well suited for a wide range of adverse environments that would not be suitable for other fruit, nut and tree crops. Leaves are alternate, the older leaves soon falling off, each leaf large (up to about $90 \mathrm{~cm}$ long) bearing leaflets in opposite pairs, with a slightly larger terminal leaflet. Leaflets are dark green above and pale on the under surface; variable in size and shape, but often round-elliptic, seldom as much as $2.5 \mathrm{~cm}$ long. The flowers are bisexual, oblique, stalked, axillary and heteromorphic and highly cross-pollinated. The carpenter bees (Xylocopa latipes and $X$. pubescens) have been found the most reliable pollinators. Sunbirds Nectaria zeylanica and N. asiatica have also been observed to be active pollinators. Flowers are produced in loose axillary panicles up to $15 \mathrm{~cm}$ long; individual flower stalks up to $12 \mathrm{~mm}$ long and very slender having 5 pale green sepals and 5 white unequal petals, a little longer than the sepals and 5 stamens. Flowers are very sweet smelling. Fruit is large and distinctive, up to $90 \mathrm{~cm}$ long and $12 \mathrm{~mm}$ broad, slightly constricted at intervals, gradually tapering to a point, 3- (4-) angled, with 2 grooves on each face and is light brown. It splits along each angle to expose the rows of rounded blackish oily seeds, each with 3 papery wings.

\section{Nutritional information of Moringa oleifera}

According to National Nutrient Database for Standard Refer. Release28 United States Department of Agriculture Agricultural Research Service, fresh chopped leaves of Moringa oleifera (approximately 100 grams in weight) have the following major constituents [3]:

\begin{tabular}{|l|l|l|}
\hline $\begin{array}{l}\text { Nutrient } \\
\text { Proximates }\end{array}$ & Unit & \multicolumn{1}{|c|}{ Value } \\
\hline Water & $\mathrm{g}$ & 78.66 \\
\hline Energy & $\mathrm{kcal}$ & 64 \\
\hline Protein & $\mathrm{g}$ & 9.4 \\
\hline Total lipid (fat) & $\mathrm{g}$ & 1.4 \\
\hline $\begin{array}{l}\text { Carbohydrate, by } \\
\text { difference }\end{array}$ & $\mathrm{g}$ & 8.28 \\
\hline Fiber, total dietary & $\mathrm{g}$ & 2 \\
\hline Calcium, Ca & $\mathrm{mg}$ & 185 \\
\hline Iron, Fe & $\mathrm{mg}$ & 4 \\
\hline Magnesium, Mg & $\mathrm{mg}$ & 42 \\
\hline Phosphorus, P & $\mathrm{mg}$ & 112 \\
\hline Potassium, K & $\mathrm{mg}$ & 337 \\
\hline Sodium, Na & $\mathrm{mg}$ & 9 \\
\hline Zinc, Zn & $\mathrm{mg}$ & 0.6 \\
\hline $\begin{array}{l}\text { Vitamin C, total } \\
\text { ascorbic acid }\end{array}$ & $\mathrm{mg}$ & 51.7 \\
\hline Thiamin & $\mathrm{mg}$ & 0.257 \\
\hline Riboflavin & $\mathrm{mg}$ & 0.66 \\
\hline Niacin & $\mathrm{mg}$ & 2.22 \\
\hline Vitamin B-6 & $\mathrm{mg}$ & 1.2 \\
\hline Folate, DFE & $\mu \mathrm{gg}$ & 40 \\
\hline Vitamin B-12 & $\mu \mathrm{g}$ & 0 \\
\hline Vitamin A, RAE & $\mu \mathrm{g}$ & 378 \\
\hline Vitamin A, IU & $\mathrm{Iu}$ & 7564 \\
\hline
\end{tabular}




\section{Culinary Uses}

Moringa oleifera is well-known for its multi-purpose attributes, wide site adaptability and ease of establishment. It is so important because of use of its leaves, pods and flowers for human consumption as well as for livestock feed. Its green pods are used as a vegetable, as an essential ingredient in the making of 'sambhar', a south Indian curry and the seed oil known as 'ben-oil' is used for cooking. Due to the rich nutrient contents, Moringa oleifera leaves are considered to be a panacea for malnutrition. Moringa oleifera contains the amino acids, argenine and histidine which are essential for infants and it is also a boon to combat malnutrition in the under-privileged regions of the world. The leaves are very nutritious with a taste resembling watercress and are sometimes eaten as a salad or in soups. Due to tough and fibrous outer skin, drumsticks are often chewed to extract the juices and nutrients discarding the remaining fibrous material. Another traditional dish which commonly includes drumsticks is Thai dish kaeng som which is a sour curry with drumsticks and fish. Tender moringa leaves, finely chopped, are used as garnish for vegetable dishes and salad. It is also used in place of or along with coriander. In some regions of India, the flowers are mixed with gram flour and spices, then deep fried into pakodas to be served as snacks or added to curries. Moringa leaf powder is an alternative to meat, because of the high protein content, especially for vegetarians. Moringa powder is more concentrated than the whole dry leaves. It can be used in many different ways such as in smoothies, yoghurt, salad dressing, garlic butter, chip or veggie dip, milk shake, on sliced tomatoes, sprinkled on popcorn, in tacos and salsas. The delicate white flowers can be sautéed and taste similar to mushrooms. Cold pressed Moringa oil has been used for cooking and in other food preparations. The bright yellow oil with a pleasant taste has been compared in quality with olive oil both having large amounts of oleic acid, however the Moringa oil does not lose its nutritional value when exposed to high heats, like olive oil does, because of its exceptional oxidative stability. Moringa oil is a great alternative in recipes that needs a nutty flavor. It is also a healthy choice to put in stir fry dishes and marinades. In African countries, Moringa leaves are used as a flavouring, and can be added to meat preparations. The dried leaves can be used as tea and also as a pot herb in the preparation of soup and porridge. After grinding, dried leaves store well for a long time and can be used as a flavouring or as a health supplement as capsule and tablet preparations. The leaves, pods, flowers and small twigs are a useful fodder for cattle, sheep, goats, camels, poultry and even fish.

\section{Medicinal uses of Moringa oleifera}

Different parts of plants are good source of potent and powerful drugs and are used in medicine in different countries. Their extracts are used as raw medicine and believed to be the important source of new chemical substances with potential therapeutic properties [4]. In many areas, particularly in the tropical countries, traditional medicinal plants remain one of the main sources in prevention and treatment of varying ailments through selfmedication [5]. Much attention has been focused on application of plant derived antimicrobials to control pathogens in foods [6]. Medicinal plants have enormous potential to synthesize aromatic substances like phenols or their oxygen substituted derivatives as secondary metabolites that serve as plant defense mechanisms against microorganisms, insects and herbivores[7]. Various parts of Moringa oleifera plant such as the leaves, roots, seed, bark, fruit, flowers and immature pods act as cardiac and circulatory stimulants, possess antitumor, anti inflammatory, antihypertensive, cholesterol lowering and antifungal activities and are being employed for the treatment of different ailments in the indigenous system of medicine, particularly in South Asia.

\section{Moringa oleifera as an antioxidant}

An antioxidant is a molecule that prevents the oxidation of other molecules. The well-known antioxidants are enzymes, vitamin $\mathrm{C}$, vitamin $\mathrm{E}$, and beta carotene. These are capable of counteracting the damaging effects of oxidation. Antioxidants are also commonly added to food products such as vegetable oils and prepared foods to prevent or delay their deterioration from the action of air. Antioxidants may possibly reduce the risks of cancer. Moringa oleifera leaves possess high phenolic content and potent antioxidant properties which may be mediated through direct trapping of the free radicals and also through metal chelation[8]. The extracts of both mature and tender leaves of Moringa oleifera have potent antioxidant activity against free radicals. These prevent oxidative damage to major biomolecules and provide significant protection against oxidative damage [9]. Further Moringa oleifera is rich in various antioxidants, including quercetin and cholorogenic acid. Moringa oleifera leaf powder can increase blood antioxidant levels. Quercetin, an antioxidant flavonol which is commonly found in apples, berries, and onions, is associated with reduced risk of coronary heart disease and stroke. Quercetin supplementation also reduces blood pressure in hypertensive rodents [10]. Rhamnose and acetylrhamnose-substituted glucosinolates are present in all of the Moringa oleifera tissues with different profiles depending on the tissue. In addition, the tissues of Moringa oleifera have a relatively complex flavonoid profile consisting of glucosides, rutinosides, malonylglucosides and traces of acetylglucosides of kaempferol, quercetin and isorhamnetin [11].

\section{Moringa oleifera in lowering blood sugar levels}


Moringa leaves may lead to reduced blood sugar levels. Moringa oleifera plant is traditionally used as an anti diabetic food. It produces structurally unique and chemically stable moringa isothiocyanates. These are the main antiobesity and anti-diabetic bioactives. These exert their effects by inhibiting rate-limiting steps in liver gluconeogenesis resulting in direct or indirect increase in insulin signaling and sensitivity. Moringa oleifera concentrate may be an effective dietary food for the prevention and treatment of obesity and type 2 diabetes [12].

\section{Therapeutic potential for the prevention of complications} during post menopause Menopause is a stage in life when a woman stops having her monthly period. It is a normal part of aging and marks the end of a woman's reproductive years. Menopause typically occurs in a woman's late 40s to early 50s. However, women who have their ovaries surgically removed undergo "sudden" menopause. Although present in the body in small amounts, hormones have big roles in maintaining our health. Estrogen hormone is commonly associated with the female body. Men also produce estrogen, but women produce it in higher levels. The hormone estrogen is responsible for the sexual development of girls when they reach puberty. It controls the growth of the uterine lining during the menstrual cycle and at the beginning of a pregnancy. It causes breast changes in teenagers and women who are pregnant. It is involved in bone and cholesterol metabolism and regulates food intake, body weight, glucose metabolism, and insulin sensitivity. The antioxidant enzyme system gets affected in post menopause due to deficiency of estrogen, which has got antioxidant properties. A study was conducted on ninety postmenopausal women aged 45-60 years to analyze the effect of supplementation of drumstick and amaranth leaves powder on blood levels of antioxidant and marker of oxidative stress. Fasting blood glucose and hemoglobin level of the subjects were also analyzed. The results indicated that these plants possess antioxidant properties and have therapeutic potential for the prevention of complications during post menopause [13].

\section{Hypolipidaemic and Chemopreventive activities of Moringa oleifera}

Moringa oleifera can lower cholesterol levels in the blood. Moringa oleifera is used in Thai traditional medicine as a cardiotonic. Recent studies demonstrated its hypocholesterolaemic effect. The studies indicate that this plant possesses antioxidant, hypolipidaemic and antiatherosclerotic activities and has therapeutic potential for the prevention of cardiovascular diseases [14]. Moringa oleifera leaves have potential in chronic hyperglycemia and dyslipidemia, as symptoms of diabetes and cardiovascular disease (CVD) risk. Reported studies in experimental animals and humans, although limited in number and variable in design, seem concordant in their support for this potential. However, before Moringa oleifera leaf formulations can be recommended as medication in the prevention or treatment of diabetes and CVD, it is necessary that the scientific basis of their efficacy, the therapeutic modalities of their administration and their possible side effects be more rigorously determined [14]. Moringa oleifera dichloromethane extract shows high antioxidant activity, potent cancer cell anti-proliferation, and induction of quinone reductase. These findings indicate the medicinal value of Moringa oleifera in terms of cancer chemotherapy and chemoprevention. Moringa oleifera leaves extracted with methanol and dichloromethane were screened for antioxidant activity. This study provided evidence that Moringa oleifera leaves possess antioxidant activity, as well as cytotoxic and chemopreventive properties. Therefore, it might be beneficial as a medicinal plant for alternative novel anticancer drugs and nutraceutical products [15].

\section{Conclusion}

The study of the different parts of Moringa oleifera is multidisciplinary and is important to the fields of nutrition, ethnobotany, medicine, analytical chemistry, phytochemistry and anthropology. Different parts of Moringa oleifera plant such as the leaves, roots, seed, bark, fruit, flowers and immature pods act as cardiac and circulatory stimulants, possess antitumor, anti inflammatory, antihypertensive, cholesterol lowering and antifungal activities and are being employed for the treatment of different ailments in the indigenous system of medicine, particularly in South Asia. Moringa Oleifera tree is the most popular underutilized tropical crop with many valuable properties of great scientific interest. The Moringa leaf is a nutritionally rich and economical vegetable available in the countries with malnutrition issues. So the production and consumption of this "green super food" should be encouraged.

\section{References}

[1] R.Dalla, "Food value of the lesser utilized tropical plant", Food Chemistry, 46, 1993, 239-246

[2] S.J. Stohs, M.J. Hartman " Review of the Safety and Efficacy of Moringa oleifera”, Phytother Res. 2015 Jun; 29(6): 796-804.e-pub Mar 24, 2015

[3] https://ndb.nal.usda.gov/ndb/foods/

[4] N.Sharma, D.S. Rathore, "Antibacterial effects of Citrus limon peel extract on human pathogenic bacteria with special reference to Urinary Tract Infection", IJSRBS,Vol.5, Issue.2, pp. 14-17, April (2018) E-ISSN: 2347-7520

[5] S. Sugandha, "Callus Induction, Anti Microbial Screening and in Vitro Plantlet Regeneration of Adansonia Digitata L.: Anendangered Medicinal Tree", IJSRBS, Vol. 2 issue 5, pp. 1016, Oct (2015) E-ISSN: 2347-7520

[6] R. Suresh,S.Thampiraj, and A. Stephen, "Antibacterial activities of wild rhizomatous plants - Curcuma aromatica, Curcuma longa (Zingiberaceae) and synergistic effects of both collected from southern Western Ghats, India”, IJSRBS, Vol. 5 issue 2, pp. 7-13, April(2018) E-ISSN: 2347-7520 
[7] H.R. Raveesha, T. Uthpala, "In vitro Callus Induction and Preliminary Phytochemical Studies of Cissampelos pareira L", IJSRBS, Vol. 5 issue 1, pp. 12-17, Feb (2018) E-ISSN: 2347-7520

[8] A. R. Verma, M. Vijayakumar, C.S.Mathela, "In vitro and in vivo antioxidant properties of different fractions of Moringa oleifera leave", Food and Chemical Toxicology, Volume 47, Issue 9, September 2009, Pages 2196-2201

[9] S.S Padma, "Antioxidant activity and total phenolic content of Moringa oleifera leaves two stages of maturity" Plant Foods Hum Nutr. 2009, Dec;64(4):303-11

[10] R.L. Edwards, T. Lyon, S. E. Litwin, A.Rabovsky,J.D. Symons, Jalili, "Quercetin reduces blood pressure in hypertensive subjects",JNutr. 2007 Nov;137(11): 2405-11.

[11] N.K.Amaglo, "Profiling selected phytochemicals and nutrients in different tissues of the multipurpose tree Moringa oleifera L., grown in Ghana", Food Chemistry Volume 122, Issue 4, 15 October 2010, Pages 1047-1054 https://doi.org/10.1016/j.foodchem.2010.03.

[12] C. Waterman, "Isothiocyanate-rich Moringa oleifera extract reduces weight gain, insulin resistance, and hepatic gluconeogenesis in mice”, Mol Nutr Food Res. 2015 Jun;59(6):1013-24.

doi: 10.1002/mnfr.201400679. Epub 2015 Apr 27.

[13] S. Kushwaha, P. Chawla, A. Kochhar, "Effect of supplementation of drumstick (Moringa oleifera) and amaranth (Amaranthus tricolor) leaves powder on antioxidant profile and oxidative status among postmenopausal women", Journal of Food Science and Technology November 2014, Volume 51, Issue 11, pp 3464-3469

[14] M Mbikay, " Therapeutic Potential of Moringa oleifera Leaves in Chronic Hyperglycemia and Dyslipidemia: A Review", Front Pharmacol. 2012 Mar 1; 3:24. doi: 10.3389/fphar.2012.00024. eCollection 2012.

[15] S.Charoensin, "Antioxidant and anticancer activities of Moringa oleifera leaves", Journal of Medicinal Plant Research Vol. 8(7), pp. 318-325, 17 February, 2014 DOI: 10.5897/JMPR2013.5353 ISSN 1996-0875

\section{Author Profile}

Ms. Amanjot Kaur pursued her B.Sc(Medical) with Gold Medal from H.M.V. College, Jalandhar and M.Sc.(Botany) with Gold Medal from G.N.D.U. Amritsar. She has teaching experience of more than 13 years. She is currently working as assistant Professor in Department of Botany, D.A.V. College Amritsar since 2004. Her area of specialization is Plant Taxonomy and ethno botany.

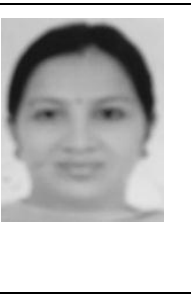

